$\begin{array}{ll} & \text { Etnográfica } \\ \text { etnográfica } & \text { Revista do Centro em Rede de Investigação em }\end{array}$

Antropologia

vol. 11 (1) | 2007

Vol. $11(1)$

\title{
O comunismo mágico-científico de Alves Redol
}

The magical-scientific communism of Alves Redol

\section{José Neves}

\section{CpenEdition \\ Journals}

\section{Edição electrónica}

URL: https://journals.openedition.org/etnografica/1884

DOI: 10.4000/etnografica. 1884

ISSN: 2182-2891

\section{Editora}

Centro em Rede de Investigação em Antropologia

\section{Edição impressa}

Data de publição: 1 maio 2007

Paginação: 91-114

ISBN: 0873-6561; E-ISBN 2182-2891

ISSN: 0873-6561

\section{Refêrencia eletrónica}

José Neves, «O comunismo mágico-científico de Alves Redol », Etnográfica [Online], vol. 11 (1) | 2007, posto online no dia 25 setembro 2012, consultado o 10 fevereiro 2022. URL: http://

journals.openedition.org/etnografica/1884 ; DOI: https://doi.org/10.4000/etnografica.1884

\section{(ब) $(1) \Theta$}

Etnográfica is licensed under a Creative Commons Attribution-NonCommercial 4.0 International License. 



\title{
O comunismo mágico-científico de Alves Redol
}

\author{
José Neves
}

Observando a importância da etnografia para o neo-realismo, este artigo toma como estudo de caso o escritor Alves Redol, figura emblemática daquele movimento literário. Começando por analisar a formação de uma sensibilidade etnográfica em Alves Redol, procuramos averiguar o significado comunista dessa sensibilidade e a sua expressão nas representações redolianas do povo e da nação. Em seguida confrontamos essas representações com a aspiração romântica de Redol a um comunismo primitivo, mas também com o seu desejo de obreirização da vida rural, mostrando por fim como Alves Redol procurou superar a dicotomia campo/cidade, afastando-se da imaginação mais urbanista de uns e da imaginação mais ruralista de outros, num processo que teve expressão máxima no Mitchurin de A Vida Mágica da Sementinha.

PALAVRAS-CHAVE: Alves Redol, neo-realismo, comunismo, nacionalismo, etnografia, tradição.

PRIMEIRO NOME DA LITERATURA NEO-REALISTA NOS ANOS 40, ALVES Redol foi um objecto constantemente manuseado nas polémicas literárias da segunda metade do século XX, no decorrer das quais a sua reputação enquanto escritor ficou seriamente abalada, mesmo entre os que eram ou haviam sido seus "companheiros de armas". Na opinião de Mário Dionísio, a escrita de Alves Redol mereceu parte das críticas que lhe foram sendo feitas, sobretudo as suas primeiras obras. No entanto, para Dionísio o erro de Redol não estava no descuidar da "forma", como apontavam vozes críticas dos neo-realistas, mas antes pelo contrário: Redol "apurava-a demais (culinariamente falando...), cedia a uma tendência infeliz mas persistente para "escrever difícil'" (Marinho e Mota Redol 2000: 79).

Críticas como esta foram sendo aceites pelo próprio Alves Redol. Em 1959, numa curta entrevista ao Jornal de Notícias, Redol reconhece que os neo-realistas haviam muitas vezes caído num erro simétrico ao "psicologismo" a que se 
queriam opor (Jornal de Notícias 1959), e alguns anos mais tarde, em 1965, a propósito de Gaibéus, o nosso autor procurava superar a polémica da forma e do conteúdo: "Necessitava de alcançar, como Gramsci escreveu, a forma vivaz e expressiva, ao mesmo tempo sóbria e contida, porque, insistindo nesse trabalho aparentemente só formal, acabaria por agir praticamente sobre o conteúdo". Confidenciando que quando "queria dizer "amor" lhe faltava a "língua", Redol assumia mesmo as insuficiências literárias dos seus primeiros tempos de escritor (Redol 1979 [1965]: 79).

A autocrítica de Redol não se ficava porém por aqui. No texto de 1965, o nosso autor tocaria ainda num outro ponto relativo ao movimento literário neo-realista, afirmando:

Precisávamos de ter um povo, criarmo-nos com ele, e caminhámos ao seu encontro sobre nuvens de ilusões, supondo que pisávamos terra firme. E julgámos muitas vezes o País pelo que desejávamos, desconhecendo que as alienações divergem (Redol 1979 [1965]: 72).

Recolocando a crítica do movimento neo-realista à luz da relação entre representação nacional e realidade social, o comentário autocrítico de Redol ilumina o problema da relação entre cultura, comunismo e nacionalismo, problema que subjaz à nossa investigação. Contudo, a desesperança das palavras de Redol faz pender sobre ele próprio um equívoco que importa antes de mais desfazer: aceitando com Redol que o neo-realismo foi uma imagem que se iludiu verdadeira, não podemos porém tomar por falsas as imagens que ele produziu. Mais do que uma falsidade envolta em "nuvens de ilusões", o neo-realismo projectou as vontades, os desejos e as ideias de uma geração de intelectuais comunistas e antifascistas, e são essas vontades, esses desejos e essas ideias que merecem análise. Por isso neste texto não nos cingiremos à obra do intelectual enquanto escritor, ${ }^{1}$ mas antes olhamos para Alves Redol escritor, intelectual comunista e etnógrafo neo-realista.

\section{ETNOGRAFIA E NEO-REALISMO}

Alves Redol nasceu no dia 29 de Dezembro de 1911. Segundo reza a lenda, as suas origens eram as mais humildes. Desde cedo que o pequeno Redol fora iniciado no mundo do trabalho, marçano numa loja da sua Vila Franca de Xira natal e, de acordo com um artigo dos anos 50 de André Parreaux - crítico literário das Lettres Françaises -, a Redol teriam ainda calhado em sorte as profissões de ceifeiro e de pescador (Marinho e Mota Redol 2000: 70). 
Hoje sabemos que a vida foi mais simpática para Redol do que reza a lenda. Como assume Inocência Redol, os irmãos Redol tiveram uma "vida de pequenos burgueses", filhos de um comerciante local em cuja loja trabalhou ocasionalmente o marçano Alves Redol (Marinho e Mota Redol 2000: 187). E como acrescenta Garcez da Silva, camarada de Alves Redol na Vila Franca de Xira dos anos 30, a primeira luta social em que Redol se envolveu foi mais da ordem da gastronomia do que outra coisa qualquer: em Lisboa, no Colégio Arriaga onde Redol esteve interno e onde concluiu o curso comercial, a qualidade do caldo verde servido desagradava-o a tal ponto que protestou sem demora contra a cozinha do estabelecimento de ensino (Silva 1993: 21).

Apenas no final dos anos 20 passaria a família Redol por algumas dificuldades - mesmo se menores - no contexto da crise económica de 1929. Acabado o curso comercial em 1927, Redol decide então seguir viagem até Luanda, onde permanece por três anos, passando por experiências profissionais que mais tarde considerou decisivas para a sua formação político-social. Em 1931, regressa a Portugal e trabalha em diferentes empregos, alguns deles em Lisboa, onde desempenha funções de chefe de escritório. Paulatinamente aproxima-se da condição de assalariado: antes de Luanda, conhece gaibéus, varinos e operários na loja do seu pai, mas o balcão demarca uma linha divisória; em Luanda, "sem amparo de família nem amor bonito de mulher minha", vive uma "vida assalariada”, trabalha na Direcção de Fazenda, dá aulas numa escola nocturna e chega a passar seis meses no desemprego (Redol 1979 [1965]: 63); e depois de Luanda percorre diferentes ofícios, viajando regularmente de comboio até à capital na companhia de operários dos Cimentos do Tejo ou da Fábrica de Loiça de Sacavém, confrontando-se com os efeitos recessivos da crise mundial de 1929 e assistindo ao despertar de pequenos núcleos comunistas na zona ribatejana.

Em Vila Franca de Xira, num ambiente político pró-oposicionista - de que é contribuinte o Mensageiro do Ribatejo, jornal criado em 1930 e extinto em 1941 onde escreveram Artur Inez, Jaime Brasil ou Julião Quintinha - constitui-se uma rede de contactos que faria daquela região um dos mais importantes territórios da história do comunismo em Portugal. Nessa rede de contactos pontuam ao longo dos anos 30 nomes como Dias Lourenço, Carlos Pato, Garcez da Silva, Soeiro Pereira Gomes e Alves Redol. Desde 1933/1934 que estes militantes se envolvem em diversas actividades de cariz político e cultural. Influenciados pelo 18 de Janeiro de 1934, sobretudo pelos acontecimentos da Marinha Grande, mas também por episódios internacionais da luta de classes como a revolta dos mineiros asturianos (Silva 1990: 114), os jovens comunistas procuraram dinamizar e organizar trabalhadores numa região onde coexistiam gaibéus, campinos e operários. Por volta de 1933, Redol e Dias Lourenço procuravam dinamizar culturalmente o Sindicato da Construção Civil e Ofícios Correlativos, distribuíam clandestinamente o Avante! (entre 1933 e 1934 
foram distribuídos entre Sacavém e Alenquer cerca de 450 jornais clandestinos, recorda Dias Lourenço), organizavam legalmente várias actividades culturais, de cursos de alfabetização a aulas de esperanto, primeiro naquele sindicato e depois em associações como o Sport Lisboa e Vila Franca (Marinho e Mota Redol 2000: 145). Mais tarde, com o apoio do jornal O Diabo e do Mensageiro do Ribatejo, Redol organizou visitas a museus de Lisboa, nomeadamente ao Museu de Arte Contemporânea e ao Museu de Arte Antiga, ${ }^{2}$ e no final dos anos 30 a formação do grupo neo-realista de Vila Franca de Xira é a consequência institucional dos esforços pela massificação da cultura desenvolvidos ao longo de toda a década. Neste período, para Redol e para os comunistas trata-se de levar a cultura até ao povo e o nosso autor é então, acima de tudo, um proficiente activista cultural.

Contudo, no processo de massificação da cultura colocaram-se desafios específicos aos intelectuais comunistas. Não lhes sendo possível iluminar as massas a partir do alto, os intelectuais comunistas necessitaram de encontrar sinais de luz no seio das próprias massas, o que favoreceu a sua adesão a uma prática de conhecimento que descobrisse tais sinais e não apenas organizasse uma campanha iluminadora. Para levar a cultura (a luz) ao povo era necessário estar disposto a descer do pedestal a fim de conhecer melhor o próprio povo e as próprias massas, conforme aconselhava $O$ Diabo aos seus intelectuais: "Uma cultura nacional deve ser um conjunto de inquéritos e pesquisas no corpo da própria nação" (O Diabo 1939: 1).

Procurando reunir conhecimento e acção num mesmo gesto - citando-se quer a proposta filosófica marxiana de que não bastaria pensar o mundo, quer a proposta política marxista-leninista de que seria necessária uma arte comprometida - os intelectuais comunistas fizeram do inquérito e da pesquisa instrumentos de trabalho privilegiados. Se por um lado estes instrumentos permitiam visualizar de perto as vidas do "povo", por outro lado permitiam ir além da contemplação - "não se recolhem os materiais da vida, vivem-se", escreveria Redol em 1967 (Redol 1968: 14) -, pôr os pés no terreno e as mãos nas massas, isto é, permitiam descer.

Gil Vicente, ele "que amou o povo e por amor dele desceu à rua", surge aqui como o modelo de etnógrafo que $O$ Diabo celebra em 1936, no quarto centenário da sua morte. Como poucas outras personagens do seu tempo, Gil Vicente teria sido "um grande mexeriqueiro da vida humana, e um partidário decidido da acção intelectual, para esclarecer, para modificar as coisas turvas e ruins deste mundo":

2 Segundo Garcez da Silva, o propósito destas iniciativas era colmatar a ausência do elemento visual na educação cultural: "O objectivo destas visitas integrava-se num amplo movimento visando a cultura do povo. Sabíamos que, enquanto o livro era de fácil divulgação, o quadro e outras peças de arte eram tesouros que não vinham facilmente até nós" (Silva 1990: p. 111 ). 
A sua obra, trepidante de vida e nela generosamente comprazida, exigia a atitude do homem que não se limita a viver de si e para si somente. Ela supõe a observação profunda dos tipos sociais; e muitas vezes teremos de supor Mestre Gil vagueando pelas ruelas dessa Lisboa quinhentista, surpreendendo a fala do mulherio, os ralhos da mãe contra a filha fantasiosa, o rondar sorrateiro do fidalgote pelintra e namorador, o propósito desajeitado e lorpa do rascão vindo à cidade dos confins da província... Outras vezes ainda - tanta é a poesia da sua obra - teremos de imaginá-lo de longada por esse Minho e por essas Beiras, acompanhando arrieiros, parado a observar os costumes dos ratinhos, tomando nota do seu falar, das suas cantilenas, e das suas dores, fixando a paisagem no homem e o homem na paisagem (O Diabo, 1936: 1).

Assim, na luta pela massificação da cultura, os comunistas foram levados à conceptualização/idealização de uma cultura popular, e foi atrás desta que partiram alguns intelectuais neo-realistas, procurando na vida do povo sinais de uma cultura indígena por revelar.

Neste movimento de partida em busca de uma cultura do povo, o percurso de Alves Redol constitui um itinerário exemplar. Influenciado pela obra de Leite de Vasconcelos, a quem elogia “a perserverança e o saber" (Redol 1938: 10), pela vocação democrática da filologia de Rodrigues da Lapa $^{3}$ e pelas representações do "povo" dos intelectuais antifascistas franceses, ${ }^{4}$ Redol realiza o estudo etnográfico Glória - Uma Aldeia do Ribatejo, de 1938, o qual marca simbolicamente o início da viagem etnográfica neo-realista. É aliás justamente pela etnografia - com a preferência pelo trabalho de campo e a prática de uma observação participante - que Redol chega ao romance. ${ }^{5}$ Sob influência de um crítico literário peruano que conhece em Lisboa, Redol dedica-se ao romance, almejando alcançar um público mais vasto do que aquele que a etnografia lhe ofereceria. Porém, quando começa a preparar o primeiro dos seus romances, o procedimento que segue é etnográfico:

3 Rodrigues da Lapa estimula Redol à pesquisa etnográfica e dá-lhe conta dos seus planos em mobilizar os estudantes de filologia da Faculdade de Letras de Lisboa, durante o Verão, para a recolha etnográfica, fazendo assim da filologia "um instrumento inapreciável de autêntica democracia" (Redol 1938: 9)

4 Na epígrafe de Glória - Uma Aldeia do Ribatejo cita-se Jean Guéhenno, director da revista Europe: "Nunca ainda se ensinou o povo ao povo", escrevia Guéhenno (Redol 1938: 7).

5 Veja-se também a carta que Carlos de Oliveira endereça a João José Cochofel em 1944, na antecâmara de Alcateia: "Um dia falaremos. Tenho algum material recolhido e escrito: o que vi, o que me disseram dois ou três velhos pescadores, o Bagão (outrora grande senhor, hoje na ruína), peixeiras, ganhões, remadores, além daquilo que eu sozinho, vi... Tenho saído ao mar com pescadores, bebido com eles nas tabernas, dançado sujo e mal falante, nos bailes pobres dos barracões. Isto em quatro dias! Estou verdadeiramente entusiasmado (e tenho, a meu favor 10 anos de praia de Mira)". Carta de Carlos de Oliveira a João José Cochofel, 14-8-1944, E23/2216. Espólio Cochofel, Biblioteca Nacional. 
Aproveitei as férias de Setembro para viver com os ranchos do lavrador Henrique Honrado, nas suas lavras de arroz na Casa Branca, junto ao Tejo, em Azambuja. Regressava ao convívio dos gaibéus com os olhos e a inteligência despertados (Redol 1979 [1965]: 69).

Neste sentido, Gaibéus (1939) deve ser lido não apenas como momento inaugural do neo-realismo literário mas também como desenvolvimento do impulso etnográfico que o antecede. Ao abrir Gaibéus com a nota epigráfica em que avisa a navegação sobre a natureza do romance - "Este romance não pretende ficar na literatura como obra de arte. Quer ser, antes de tudo, um documentário humano fixado no Ribatejo. Depois disso, será o que os outros entenderem" (Redol 1979 [1939]: 82) - mais do que se indignar contra um pretensiosismo artístico de meios literários, Redol alumia a sua vontade etnográfica. ${ }^{6} \mathrm{O}$ neo-realismo nasce assim como um movimento intelectual pronto a acolher interpelações não literárias da realidade, predispondo-se nomeadamente a desempenhar as vezes de um conhecimento científico marxista que não teve oportunidade de existir, vedado que foi o seu acesso à universidade. Em 1951, a propósito de Os Homens e as Sombras (1951), Mário Dionísio sublinhava esta dupla funcionalidade do trabalho literário de Redol e nela situava a oposição entre o neo-realismo e os seus rivais: "Há pelo menos doze anos que Alves Redol trabalha incansavelmente com o fito de conseguir uma maturação literária que lhe permite a fusão harmoniosa do romance e do documento humano e nacional" (Dionísio 1951: 501).

Ao longo da vida de Redol, a atracção da pesquisa de tipo etnográfico foi uma recorrência a que, por exemplo, correspondeu a sua dedicação aos cancioneiros. Em 1940, num texto sobre "O trabalho no Cancioneiro do Ribatejo", Redol elegia a recolha da memória oral como via de acesso a um registo escondido (Scott 1985) que guardava alternativas a uma versão dominante da história - "porque as leis que os arquivos guardam não são feitas pelo povo" (Redol 1940a: 3) escrevia então Redol influenciado pela experiência dos cursos sindicais nocturnos em que leccionara nos anos $30 .{ }^{7}$ Mais tarde, por volta de 1950, a sua faceta etnográfica reassumia-se, terminando por fim o seu Cancioneiro do Ribatejo, realizando pesquisa no âmbito dos trabalhos de investigação que preparam França - da Resistência à Renascença, e iniciando o projecto de um cancioneiro popular do Douro. Aliás, depois do Ribatejo, a região mais querida a Redol foi o Douro. Desde 1943 que visitava a região duriense, nomeadamente

6 No caso da frase de abertura de Cacau, o famoso romance de Jorge Amado, aí sim parece dar-se um levantamento contra a chamada "arte pela arte", mesmo se não se perde de vista a ambição documentarista: "Tentei contar neste livro, com um mínimo de literatura para um máximo de honestidade, a vida dos trabalhadores das fazendas de cacau do sul da Bahia” (Amado 1936 [1933]: 1).

7 "Ensinei bem pouco no sindicato, mas aprendi muito do que hoje sei no convívio dos meus alunos" (Redol 1979 [1965]: 64) 
as zonas vinhateiras, e essas primeiras visitas deram origem a um primeiro romance em 1946, Porto Manso. Agora, em finais dos anos 40, Redol regressava à região, passando aí largas temporadas das quais resultou a série literária Ciclo Port Wine (Horizonte Cerrado em 1949, Os Homens e as Sombras em 1951 e Vindima de Sangue em 1953), e nas quais iniciou pesquisas para o cancioneiro do Douro. Revalorizando os saberes das populações locais, nomeadamente dos idosos, Redol propunha perscrutar os mais variados aspectos da vida social da região, imbuído de um sentido de urgência que já se manifestara literariamente em Porto Manso, onde a irrupção do comboio ameaça os hábitos e os costumes locais $^{8}$ (o projecto do cancioneiro duriense nunca chegaria a ser concluído). Para este efeito, Redol entregou a amigos e conhecidos da região um pequeno documento intitulado "Breve nota para o recolhedor do cancioneiro popular do Douro" (Marinho e Mota Redol 2000: 287), através do qual procurou orientar os "recolhedores" e despertar-lhes o gosto pela pesquisa etnográfica. ${ }^{9}$

Não foi apenas nesta ocasião que Redol quis fazer da etnografia um hábito de grupo. Também noutras circunstâncias o nosso autor procurou envolver os seus companheiros neo-realistas em projectos de tipo etnográfico, convocando-os para se juntarem em trabalho de campo. Em 1953 Redol fez parte do grupo de artistas-etnógrafos do conhecido Ciclo do Arroz, projecto que levou Júlio Pomar, Rogério Ribeiro, António Alfredo, Cipriano Dourado, Lima de Freitas e o próprio Redol a percorrerem os arrozais ribatejanos, numa experiência colectiva que teve o seu expoente artístico na série Ciclo do Arroz pintada por Pomar nesse mesmo ano. Esta célebre iniciativa não constituía novidade para alguns daqueles artistas neo-realistas. Em 1944, projectando a publicação de um livro colectivo centrado no comércio do peixe na lota de Lisboa, Redol havia já reunido à sua volta Júlio Pomar, Mário Dionísio e Sidónio Muralha, e porque tudo se deveria basear na observação directa, os quatro se encontravam pela alvorada a fim de em conjunto percorrerem a lota de Lisboa. ${ }^{10}$ Eis o testemunho de Mário Dionísio:

Encontrávamo-nos no Cais do Sodré e penetrávamos, maravilhados e de bloco em punho, naquele mundo que fervilhava entre o rio e a estação ferroviária, enquanto a cidade dormia. Pelo cais fora, era uma azáfama surda de inúmeros vultos no escuro, uma grande massa em movimento entre os

8 “[... é ninho de barqueiros - mestres, arrais, feitores, marinheiros e moços -, que vivem do rio e para o rio, numa tradição que se não quebra, porque a vida não lhes oferece outro caminho. Pátria de melros conhece-lhes o assobio. Mas outro assobio mais forte e angustioso retalha o silêncio, que ali mora - o do comboio que passa lá acima, estremecendo as casas e retalhando o coração dos homens" (Redol 1999 [1946]: 26).

9 O documento surge em anexo no final deste artigo.

10 As pesquisas na lota de Lisboa não deram origem a nenhum livro. Ela marcou todavia alguns quadros de Júlio Pomar datados da década de 50 - Mulheres na Lota e A Lota - e ainda uma tapeçaria de Dionísio de 1953 (Marinho e Mota Redol 2000: 58). 
barcos e a doca e ao longo dela, que pouco a pouco se ia definindo até se encher de cores vibrantes e ruído mal o sol rompia. Pescadores, peixeiras de xailes grossos e tamancos, carregadores, fiscais e guardas-fiscais, crianças em canastras, os carros do café e da aguardente, o frenesi da lota... Queríamos ver tudo, metíamos conversa, abancávamos a "matar o bicho" com algum marítimo de momento desocupado (Marinho e Mota Redol 2000: 68).

\section{EXOTISMO E TRADIÇÃO EM ALVES REDOL}

Quando foi para Angola em 1928, Alves Redol era um jovem de 16 anos de idade, verdadeiramente entusiasmado com a aventura em que se lançava. Por si só, a viagem de barco até Luanda representou um novo mundo, conforme revelam as impressões que deixou no jornal Vida Ribatejana. No barco, o simples beliche - "sala de club, um mixto de jogo e de restaurant, um confessionário de vidas, de ilusões, de temperamentos..." (Redol 1928b: 4) - era motivo de mil histórias e os companheiros de viagem também ajudavam à festa: se não era um "colonial formado em barbas, caças e mentiras" era a loira que cantava "o seu corpo, o seu rosto e talvez a sua alma" na sala de fumo (Redol 1928c: 3). Aos olhos do jovem Redol, para quem as danças das mulheres do barco eram "a cocaína que nos dão, uma cocaína que se vende a todos os passos e que não foi proibida”, tudo era cada vez mais intenso (Redol 1928b: 4).

Mas se o interior do barco oferecia um mundo novo, que dizer do mundo lá fora? Para além da Madeira, o itinerário fez o barco ancorar em outras ilhas atlânticas sob domínio português. Redol ficou particularmente encantado com São Tomé, uma "pérola africana" que se levantava no meio do oceano qual "padrão ao nosso patriotismo", fazendo "recordar ao mundo o nosso Empório Colonial" (Redol 1928e: 4). A descoberta do novo mundo fez Redol orgulhar-se do seu Portugal - "Cada vez que falam de Portugal, eu, como todos os outros, sinto dentro de mim uma comoção forte” (Redol 1928c: 3) - e não lhe era fácil mitigar a "saudade" (até porque no barco seguia um degredado que teimava em cantar com voz rouca um "fado triste" que "albergava toda a dor da sua alma portugueza” (Redol 1928d: 3). Desembarcado em Luanda, Redol promete trazer aos leitores do Vida Ribatejana, daí em diante, as histórias dos feitos dos portugueses em Angola, dando testemunho "às virtudes religiosas e cívicas, que de fracos mortais fizeram heróis". Homenageando essas "edades homéricas", os seus textos adoptam um tom que dificilmente poderia ser mais épico:

Os Lusitanos partiram sempre. Deixando o horto ou a serrania, o mar ou a arte, envoltos num desejo de descobrir terras desconhecidas, de dar ao seu reino novos empórios, singravam ao mar em busca de florestas de oiro, de quimeras encantadas, onde outro qualquer povo não tivesse chegado, onde só a bandeira das quinas pudesse governar! (Redol 1929a: 5). 
Nos artigos escritos a partir de Luanda, Redol elogia a obra desenvolvimentista de Norton de Matos, lamentando a falta de apoio económico dos poderes políticos em Lisboa aos governos coloniais e duvidando das promessas de ressurgimento feitas pela ditadura (Redol 1929b: 5). Contudo, em 1930, quando é aberta uma linha de crédito para os colonos, o jovem Alves Redol fica convencido "de que o Governo da Ditadura está disposto a levar a efeito a grande obra colonial que traçou no seu programa" e agradece a nova medida ao ministro das finanças Oliveira Salazar (Redol 1930: 2). A aventura africana reconfirmava assim o orgulho nacionalista de Redol, e no regresso a Portugal, em 1931, com 19 anos de idade, o jovem vila-franquense mantém desperta a esperança depositada no projecto imperial português. ${ }^{11}$

Regressado de Angola, Redol vai procurar reencontrar o exótico na tradição. Em 1932, Redol vem sublinhar a importância da relação entre exotismo e tradição na construção do espectáculo moderno. Elegendo a tradição como via fulcral para a modernização da vida social, defende um aggiornamento da feira de Vila Franca de Xira. Afirmando que "só um ou outro velho - de físico e de espírito - se entretém a olhar para o passado, cantando endechas à nossa feira", propõe "defender a feira de Vila Franca dando-lhe aspecto moderno" e apela à ideia de modernismo:

Eu sei que isto de modernismo, é uma palavra que se usa pouco cá pelo burgo e soa mal a certos ouvidos. Mas é inevitável a rendição. A arte moderna tem a essência da nossa época, está cheia de dinamismo vertiginoso desta década maravilhosa, e isso fez trocar o passo a muita gente que já arrasta os pés e ainda mais o espírito.

Para Redol, a única coisa que se salvava na feira era a "espera dos toiros"12 "única nota bizarra, cheia de colorido e de entusiasmo, que sacudiu o torpor do nosso ronceirismo provinciano" -, mas também a este nível se impunha a necessidade de inovar: "Aqueles campinos das esperas não poderiam ter envergado o seu verdadeiro e autêntico traje, tão garrido e interessante, se alguém

11 Em 1934, numa fase em que já se encontraria mais próximo de ideias comunistas, Redol profere uma conferência em Vila Franca de Xira, intitulada “Terra de Pretos - Ambição de Brancos”, na qual se centra nas condições geográficas e nas potencialidades económicas de Angola sem aflorar assuntos directamente relacionados com a exploração colonial (Marinho e Mota Redol 2000: 340). Em 1936, no entanto, Redol chega mais longe na crítica do colonialismo do que muitos comunistas dos anos 40, denunciando os que supunham os negros como "raça sem destino histórico" pronta a "suportar ensaios de colonização" (Redol 1936a: 1).

12 Já em 1927, com 16 anos de idade, Redol via no espectáculo da tauromaquia a possibilidade de um desenvolvimento da região: "Os nossos organizadores dormem, enquanto nós pedimos toiros e a terra pede desenvolvimento comercial. Sim, a terra pede desenvolvimento, quanto à parte tauromáquica, porque ela dá à terra uma alegria desusada, uma outra aparência mais citadina e impulsiona a pequena esfera de acção em que se encontra actualmente o nosso comércio" (Redol 1927: 2). 
cuidasse destes pequenos nadas, que constituem a beleza do espectáculo?" (Redol 1932: 1). Posteriormente, em 1934, no seu aplauso ao filme de António Lopes Ribeiro, Gado Bravo, Redol chama a atenção para a dimensão internacional destes processos de invenção da tradição. Aludindo a um processo cinematográfico de "técnica sensivelmente idêntica" que teria por objectivo aproveitar "as características mais definidas da nação", Redol saúda Gado Bravo por vir acrescentar a figura dos campinos portugueses aos cow-boys americanos e aos reis da França por hábito exibidos no cinema (Redol 1934: 1). A sofisticação dos comentários de Redol sobre as condições de produção do espectáculo testemunha bem a sua concepção modernista do valor da tradição, à qual não será alheia a influência que António Ferro sobre ele exerceu. ${ }^{13}$

Em 1936, em "Kangondo", um pequeno conto que Redol submete a publicação em O Diabo, o nosso autor retoma África enquanto objecto de escrita. Agora o seu posicionamento político comunista leva-o a afastar-se de um discurso pró-colonialista, mas permanece bem viva a tendência para representar exoticamente a realidade. O conto é a tal ponto bem acolhido pela redacção que a partir desse momento Redol torna-se colaborador regular do jornal (Silva 1993: 113). O enredo de "Kangondo" resume a história de uma mulher negra e africana vendida por seu pai - um chefe tribal - a um homem branco e europeu mas, para a redacção de O Diabo, tão ou mais importante do que este enredo terá sido o estilo incutido por Redol na descrição da paisagem e na caracterização das personagens. Em "Kangondo", as cores disparam em todos os sentidos (o dorso verde-negro do rio Bengo, as cintilações de oiro do Sol, os cachos amarelo-vermelho da palmeira, os panos garridos das mulheres), o tempo mede-se na passada de um animal felino (para chegar de um lado ao outro do rio demoramos "três saltos de tigre quando muito"), os coqueiros têm "cabeleiras curtas e desgrenhadas" tal como os humanos, as mulheres transportam "carnes bronzeadas de pimpolhos" sobre o dorso tal como os animais, e a sexualidade irrompe inusitadamente, com os seios da mulher erguendo-se “opulentos e agressivos pela sazonação da líbido" (Redol 1936b: 2). Ou seja: em "Kangondo" a natureza é mais humana e a humanidade é mais animal - num processo de antropomorfização e de desumanização que se projecta na representação da mulher negra - prolongando-se assim as principais linhas de um poema escrito por Redol na última fase da sua estadia em Angola: intitulado "Poente", o poema de 1930/1931 celebra o fim de dia "sereno, tropical" através da imagem de um "beijo maternal" que o Sol lança sobre a Terra enquanto as "negras" passam "levadas pelo vento" (Redol 1931: 4). ${ }^{14}$

13 "Lembro-me ainda de que o Forjaz de Sampaio me tornou ácido durante um tempo e que o inconformismo aparente de António Ferro me alapou com girândolas de imagens futuristas" (Redol 1979 [1965]: 60).

14 Sendo porém certo que o enredo de "Kangondo" procura dar visibilidade às relações de poder no mundo colonial, rompendo com a celebração imperial dos escritos luandenses de Redol. 
Depois de "Kangondo", e apesar de abandonar África enquanto cenário literário e se dedicar ao Ribatejo, Redol mantém um estilo exotizante nos textos que publica em $O$ Diabo. Tal como em Angola, no Ribatejo o rio é tanto uma espécie de pai-natureza que "copula a terra [...] onde pousa os lábios" como o senhor do tempo que marca o passo aos homens e às mulheres, "o relógio colectivo das horas boas e más dos habitantes das suas margens”, que continuam a surgir como personagens que se limitam a reflectir o exotismo da natureza. Se com o Bengo a "passarada desfiava rosários de melodias", com o Tejo o rio vem "cantando de longe a trova do seu destino" (Redol 1937a: 4). ${ }^{15}$ Num caso como no outro, basta uma aventura que o mova no espaço para Redol descobrir todo um novo mundo. Na sua imaginação das distâncias espaciais - entre metrópole e colónia (Portugal e Angola) e entre cidade e aldeia (Lisboa e Glória) - traça-se uma fronteira que descontinua o percurso entre o lugar de partida e o lugar de chegada, atribuindo-se a cada qual um tempo de natureza diferente: por um lado há o tempo da civilização (o tempo da metrópole e da cidade) e por outro lado há o tempo do primitivismo (o tempo da colónia e da aldeia). ${ }^{16}$ Trata-se pois de romper o tempo em dois através de um simples movimento espacial, alimentando assim a aspiração a um outro tempo.

Todavia, entre os textos africanos e os textos ribatejanos de Redol, existe uma dissemelhança que não é de somenos, dissemelhança que começa por revelar as influências teóricas de Paul Lafargue - em 1940 Redol reconhece ter sido Lafargue quem o ensinou a procurar nas canções populares as relações sociais de cada época ${ }^{17}$ - e sobretudo de Totem e Tabu, obra de Freud de que Redol foi um leitor devotado, conforme sublinhou Garcez da Silva (1990: 1940). ${ }^{18}$ Depois de Totem e Tabu, em Redol o exotismo passa a ser codificado pela simbologia totémica. ${ }^{19} \mathrm{Na}$ crónica "A Cheia" é precisamente o enfurecimento do totem, "espírito supremo dos destinos da região", que está em causa: o totem, que "dera a todos igualmente a bênção fecunda das suas águas, ricas de nateiros e de peixes", pune o homem por intermédio das cheias porque o homem teima em "modificar a obra sublime e de proveito comum que [o totem] concebera e pretendia ver realizada". Agora, nos textos ribatejanos, é como se o exotismo da natureza simultaneamente precedesse e excedesse a materialidade dos corpos físicos, apresentando-se como um princípio ordenador que constitui simultaneamente uma origem histórica (um passado) e uma lei histórica (um futuro): "Em épocas remotas, quando o subconsciente das religiões

15 Mesmo se Redol se socorre da figura mais clássica do "andamento 'mobile" (Redol 1937a: 4).

16 Veja-se a este respeito o clássico trabalho de Johannes Fabian (1983: 11) e também a obra seminal de Michael Löwy e Robert Sayre (1997: 34).

17 Alves Redol, "O trabalho no Cancioneiro do Ribatejo", O Diabo, p. 3, 17-8-40.

18 Aos temas do totem e do tabu dedicará uma conferência em 1939 (Silva 1990: 140).

19 Em Glória - Uma Aldeia do Ribatejo, Redol refere-se também a Hubert, Mauss e Reinach, mas é sem dúvida Freud a sua referência principal (Redol 1938: 185). 
regulava a vida dos clans e as relações das tribus, creio bem, era o Tejo o totem dos grupos comunais que viviam nas suas ribas" (Redol 1937a: 4).

Esta codificação totémica revela em primeira instância a influência da proposta científica de Freud em Redol, mas num segundo momento podemos perceber que ela reflecte igualmente a transformação política de Redol. Na verdade, através da codificação totémica Redol quer preservar um ideal de comunismo ao qual adere em meados dos anos 30. No exotismo da natureza representado por Redol, o ideal comunista encontra-se simultaneamente adiado (como se fosse uma origem histórica) mas prometido (como se fosse uma lei histórica), funcionando a natureza como paradigma de um ordenamento comunista da vida e emergindo o passado primitivo como um molde para um novo futuro. Isto é proposto por Redol em Glória, onde o nosso autor encontra vestígios totémicos na população da aldeia (Redol 1938: 186), mas também permanece nos seus textos posteriores, como Gaibéus, onde "as rãs coaxam a sua liberdade":

Estava noite de luar. Um luar brando de Outono que vestia as coisas de penumbra triste. Piscavam luzes na outra margem, dispersas aqui e além, mais ali reunidas, como num concílio de estrelas. Eram constelações de vidas, todas iguais vistas de longe. A luz que iluminava o senhor não brilhava mais do que a outra que alumiava o servo. Ali não havia casebres, nem palácios. Todas eram irmãs, como as estrelas da Estrada de Santiago que polvilhavam de oiro o azul-negro (Redol 1979 [1939]: 253).

Preservando a natureza o segredo de um ordenamento alternativo do mundo, Redol define um sentido político próprio para a sua etnografia: a ela cabe descobrir a diferença da natureza face aos modos de vida dominantes do capitalismo. Ou seja, tendo o comunismo uma origem primitiva, há que descobrir essa origem, fazer dela um património e procurar antes de mais preservá-la. Nos anos 60, em jeito de retrospectiva, Redol resumiu a importância que estes novos descobrimentos tiveram para si:

Numa visita que fiz à Lezíria Grande com Rodrigues Lapa, tendo por anfitrião o malogrado lavrador-poeta Pompeu Reis (poeta pela paixão com que cuidava da terra que nem era sua), descobri a gente da Glória, tão diferenciada no vestuário como nos hábitos de vida e de trabalho dos outros alugados dali. A veia romântica abriu-se-me para o invulgar desse povo sequestrado por ele próprio entre Marinhais e Coruche (Redol 1979 [1965]: $67)$.

No pequeno espaço da aldeia da Glória, Redol descobriu diferenças suficientemente absolutas para nelas descortinar a possibilidade de um novo mundo cuja promessa diz conservar-se na vida daquela pequena aldeia. $\mathrm{O}$ elogio de 
Redol a um "povo sequestrado por ele próprio", associando o comunismo ao comunitarismo, é o corte que permite determinar a diferença.$^{20}$ Nessa "gente da Glória" tão diferente dos seus próprios semelhantes (os "outros alugados dali") encontravam-se os sinais esperançosos de um outro tempo que reabrem "a veia romântica" de Redol, colocando-o na desejada posição de completo estranhamento: aos olhos de Alves Redol, Glória é tão diferente como fora Luanda, e a tradição torna-se assim o lugar do exótico, não havendo para Redol imperativo mais premente do que a sua preservação. ${ }^{21}$

\section{DO CAMPINO AOS GAIBÉUS}

Pesem embora as transformações verificadas entre o Redol colonialista dos textos africanos e o Redol comunista dos textos ribatejanos, há algo que permanece intocável, em particular em Glória - Uma Aldeia do Ribatejo: a sua política de valorização das identidades. É certo que em Glória - Uma Aldeia do Ribatejo, Redol propõe substituir o conceito de "raça" pelo de "etnia", alegando que falar de "raça" num país como Portugal, "em que as invasões se sucederam num ritmo vivace, quási trepidante, é criar imagem de estrofe para fins emotivos" e assim esquecer "em fantasias as conclusões que os antropólogos nos legaram” (Redol 1938: 23). É certo que, ao longo dos anos 30, Redol se distancia do trabalho de artistas como António Lopes Ribeiro e de concepções de intelectuais como António Ferro, e que em 1936 ele procurava demarcar o seu exotismo de leituras mais racialistas, promovendo noções de identidade menos irredutíveis ao exterior e criticando a ideia de uma predisposição rácica dos povos (Redol 1936a: 1). É certo também que em 1937 ele remete a origem da figura do campino à mais impura das heranças étnicas:

Por aqui andaram os árabes em correria, na planura vasta das terras chãs, cavalgando seus ginetes nervosos e ágeis como os ventos do deserto. Deles herdaram os campinos o porte galhardo do seu busto airoso, o segredo de domar corcéis e a valentia pimpona com que dominam toiros (Redol 1937b: 7).

Contudo, no campino de Redol mantém-se operativa a ideia de uma diferenciação identitária: ele é irmão do "beduim dos desertos arenosos e do vaqueiro

20 Em 1938, nas primeiras páginas de Glória - Uma Aldeia do Ribatejo, Redol sublinha desde logo esta autodeterminação da aldeia: "Não conheço em todo o Ribatejo percorrido, aldeia que irradie mais simpatia por atributo próprio" (Redol 1938: 15).

21 Veja-se neste sentido de comemoração de uma tradição comunal primitiva, a contribuição de Vítor de Sá ao $1^{\circ}$ Congresso de Etnografia e Folclore, em 1956 (Sá 1963 [1956]: 368). Também o interesse que Redol mostrou pela musealização - Redol projecta um Museu Etnográfico do Ribatejo e um museu sobre o Tejo - se enquadra nesta perspectiva de fixação e tradicionalização da vida rural que atravessa toda a sua obra literária. 
das pampas argentinas", mas ele contrasta "com a hostilidade agressiva do primeiro e a ufania brigona do segundo" (Redol 1937c: 7). Por isto não nos surpreende que quando é publicado Glória - Uma Aldeia do Ribatejo, surjam de pronto em $O$ Diabo elogios a essa aldeia "onde tudo recorda um Passado de pitoresco e de cor étnica"22 (Brito 1938: 7).

Dos anos 40 aos anos 60, esta sensibilidade étnico-identitária de Redol continuou sempre presente, podendo até equacionar-se se ela não terá ganho novo impulso no pós-guerra, período em que Redol escreve França - da Resistência à Renascença. Nesta fase, Redol escreve também o seu maior ensaio sobre o Ribatejo, um texto publicado na obra Portugal Maravilhoso (dirigida por João de Barros), em que elogia uma vez mais a Etnografia Portuguesa de Leite de Vasconcelos (Redol 1945-1952: 93), e em que retoma Freud a fim de comparar os hábitos rituais dos Maori e os hábitos rituais dos glorienses, corroborando a celebração internacionalista da cultura dos povos que foi apanágio do pós-guerra. Porém, neste ensaio em que se perde em elogios à aldeia da Glória e em que celebra os Maori, Redol também recusa a idealização de um meio ambiente predominantemente rural. O seu maior elogio no ensaio vai mesmo para a figura do operário valador, que combate as cheias do Tejo e cuja luta é "mais heróica que nenhuma outra" (Redol 1945-1952: 150).

Neste elogio ao valador, Redol sela a ruptura com a figura do campino, desenvolvendo algumas das reticências que sobre ela acumulava desde a segunda metade dos anos 30. Em 1937, em O Diabo, Redol havia consagrado uma crónica à figura do campino na qual, o elegia habitante tipo do Ribatejo, devido ao "traço inconfundível da sua indumentária colorida, bela entre a exuberância dos trajes portugueses" e "à rudeza e valentia da sua faina, envolvida das lendas galhardas da nossa cavalaria de antanho"; porém, já então Redol se recusava a celebrar por inteiro a identidade campina, comentando que à bravura do campino diante do toiro se contrapõe a sua atitude de idolatria face ao patrão, atitude própria da "ancestralidade do servo da gleba" (Redol 1937c: 7). A valorização comunista do valor social e político da classe operária começava aqui a fazer-se sentir, mesmo se de forma ainda incipiente. Em 1939, com Gaibéus, Redol faria do trabalho operário um elemento fundamental, procurando revigorar o idílico tempo da aldeia através das energias operárias do tempo da cidade.

Em Gaibéus, na estreia do neo-realismo literário, o trabalho é quem mais ordena. Em vez de um enredo cadenciado por relações pessoais de índole

22 Antes do elogio a Glória, Nogueira de Brito havia aliás publicado em O Diabo um artigo sobre o tango, onde dava vazão a lugares comuns aos que Redol utilizaria em "Kangondo", publicado um mês depois do artigo de Brito. Sobre Buenos Aires, Brito relatava a "promiscuidade das mesas" nos cafés convivendo com "policromias exquisitas" numa "aglomeração de rostos e de corpos" em que os "sexos se roçam em delírios de prazer" e onde por fim sobressaía uma "flor exótica" de seu nome "Pepa Moreno", dançarina de tango com os seus 14 anos de idade (Brito 1936: 3). 
familiar, amorosa ou política, tudo se centraliza no mundo do trabalho. Em vez de nomes e histórias de vida, as personagens ganham densidade através das descrições exaustivas dos seus corpos trabalhando. Estes corpos são decompostos a um tal ponto que, mais do que um corpo que trabalha, existem extensões que reagem por instinto - a fadiga ataca "as carnes", "as mãos limpam as frontes", "as bocas movem-se a resmoer, querendo segregar a humidade que não vem mais" - sob o automatismo do processo produtivo: "Nas camisas dos homens desenham-se as omoplatas, agitadas como êmbolos cansados pelo mover das foices e pelo amontoar das espigas" (Redol 1979 [1939]: 109). Os corpos surgem assim definidos pelos próprios termos mecânicos/maquinais: é o arfar dos peitos "num ritmo de máquinas velhas saturadas de movimento" (Redol 1979 [1939]: 199), são os corpos sem lugar para o pensamento porque se trata de máquinas cujos movimentos são impostos pelos volantes, é o "caminho mecânico" das pernas. Enfim, "não param as máquinas - não param os homens. Ali não há homens - há máquinas. Só máquinas” (Redol 1979 [1939]: 282).

O significado da descrição maquinal dos corpos que trabalham é imenso. Através de uma paulatina transição de um modelo natural de actuação dos corpos que trabalham para um modelo maquinal de funcionamento, Redol quer falar não de trabalho em geral mas de trabalho operário em particular, isto é, quer afirmar que é de operários que se deve falar quando nos referimos aos ceifeiros e às ceifeiras (mesmo se de operários com laivos de pequenos proprietários camponeses). ${ }^{23}$ Antecipando-se à mais intensa mecanização da produção agrícola, Redol mostra como o desenvolvimento da exploração laboral faz os corpos dos gaibéus funcionarem como máquinas. Assim, é tendo o campo por cenário que se inicia o divórcio entre homem e natureza, com o tempo da produção industrial capitalista a se divorciar do tempo da natureza: a sede chega primeiro aos corpos que trabalham e só depois é que a hora da pausa para a água chega ao relógio dos capatazes; e o "poente", forçado pela disciplina de trabalho imposta pelos capatazes, acontece nos corpos dos ceifeiros antes do tempo naturalmente devido - "o poente vem longe - nos corpos dos ceifeiros já é poente” (Redol 1979 [1939]: 114). Contudo, é também assim que o homem inicia a sua libertação face à natureza, libertação esta que se traduz de forma muito clara na aspiração à mobilidade que marca Gaibéus.

Gaibéus são os que descem do Alto Ribatejo e da Beira Baixa até às lezírias, fazendo do Ribatejo um lugar da síntese mais do que uma paisagem pastoral ou contrapastoral. Conforme definirá Redol no ensaio "Ribatejo" publicado na

23 "Nunca patrão algum lhe tirara remoque por desmazelo no trabalho. Ele pertencia à família dos Milhanos de Marinhais, sempre famosos no Ribatejo como arrozeiros sabidos e safos de mandria" (Redol 1979 [1939]: 84). "Mas também a alegria de ver todo o arrozal farto de espigas o dava por bem pago no fim do contrato" (Redol 1979 [1939]: 85). 
obra Portugal Maravilhoso, à excepção da recôndita aldeia da Glória, o Ribatejo é uma "região aberta" que "se tem prestado a receber influências dos emigrantes", implicando esta particularidade uma maior atenção etnográfica ao trabalho, já que é por ele que os migrantes chegam ao Ribatejo: "Quem quiser fazer estudo sério do seu folclore, principalmente, não poderá esquecer as relações de trabalho que explicam e documentam certos aspectos da vida do ribatejano" (Redol 1945-1952: 150). A mobilidade do trabalhador, elemento fundamental no desenvolvimento do capitalismo, torna-se assim condição do próprio comunismo de Redol, marcando a sua imaginação das relações campo-cidade e também, claro está, o seu internacionalismo. Em 1939, na abertura da novel página literária do Mensageiro do Ribatejo, Redol anuncia esse espaço como "um porto franco para todos os homens que não esqueçam a sua condição humana, e não olvidem, principalmente, o que devem a outros homens, de todas as raças e de todos os cantos do mundo" (Redol 1939: 3), e em Gaibéus a margem ribatejana é o "Porto de Todo o Mundo". E se na figura do ceifeiro rebelde definido como elemento de vanguarda - "o ceifeiro rebelde tem bússola" (Redol 1979 [1939]: 126) - a emigração pode ainda ser lida como uma falsa esperança (Ferreira 1992: 115), entre os demais gaibéus a vontade de emigração corporiza o despojamento integral da condição proletária, livre de tudo o mais para além das suas próprias grilhetas:

Ali era o cais de embarque e mais outro companheiro esperava também o momento de abalar. Não tinham malas, nem sacos e isso bastava aos emigrantes.

As estrelas no céu prometiam-lhes boa viagem.

E interrogavam-se, mudos.

Reviam todo o sonho acalentado durante cinco anos. Imaginavam as cidades e os campos da nova pátria, onde iriam trabalhar - trabalhar em quê? ...

Em tudo o que braços humanos pudessem pegar. Não havia melindres na escolha, nem hesitações. Começariam outra vida, mais dura talvez, mas mãe (Redol 1979 [1939]: 259).

A água surge então como o líquido mais precioso na narrativa de Redol, porque a sua fluidez é a condição da mobilidade laboral dos gaibéus que descem do Norte, e é precisamente do estuário do Tejo, ${ }^{24}$ onde o rio se confunde com o mar, que o mundo se abre ao trabalho operário - o ceifeiro rebelde "também já andara por esse mundo, embarcado como mercadoria” (Redol 1979 [1939]: 254) - fazendo dele o corpo internacionalista por excelência:

24 Redol pensou em conceber um Museu do Tejo e foi o Tejo que elegeu como tema para a conferência que proferiu na Sorbonne no final dos anos 40. 
[...] o desejo de abalar dominava-os a todo o momento. [...] Já lá ia em cinco anos que aquela ideia os tomara; desde então, nunca se desprendera deles. Agora tornara-se parte integrante do seu corpo - como se aquele rumo lhes fosse marcado no berço por fatalismo. Nunca lhes dera para se prenderem a um rancho e virem à Lezíria fazer uma temporada larga (Redol 1979 [1939]: 257).

Esta concepção redoliana de um corpo internacionalista em 1939 responde de frente ao clima racialista dos anos 30 e prossegue-se em Nasci com Passaporte de Turista, pequeno conto de 1940 cujo enredo enaltece a condição pós-nacional de um judeu europeu que, sob perseguição nazi, ganha alento na figura de seu pai, um operário morto na Hungria de 1919 na revolução de Bela Kun (Redol 1940).

\section{O LABORATÓRIO-POMAR DE MITCHURIN}

Desde finais dos anos 20 que se fez sentir em Alves Redol a urgência de descobrir um outro tempo que não este. Em 1962, ao jornal República, Redol assumia esta urgência como um elemento fundador da sua obra literária:

A obra literária tem sempre o sabor duma aventura que não se pode recusar, como quem prepara uma viagem ao desconhecido e aceita apaixonadamente em pleno drama das interrogações e das dúvidas... (República 1962: 14).

Nos seus primeiros textos, os textos africanos de finais dos anos 20, a aventura significava o deslocamento da metrópole até à colónia. Num segundo momento, no final dos anos 30, nos textos ribatejanos e em Gaibéus, a viagem levou-o da cidade até à aldeia. Entre os dois momentos existe porém uma diferença que não é menor. Se no primeiro momento Redol procura reinventar e fazer ressurgir a metrópole através da colónia, tomando a segunda como um instrumento da primeira, no segundo momento Redol procura uma transformação da relação entre centro e margem e não apenas uma renovação da cidade através da colonização da aldeia. Assim, Redol fixa-se numa tensão - ruralizar a cidade, urbanizar a aldeia - que atravessa a generalidade da sua obra de então em diante. Nos anos 40, em Porto Manso (1946), quando viaja pela primeira vez até ao Douro a fim de retratar a vida de uma pequena comunidade aldeã, Redol coloca-se a si e à aldeia entre dois braços, um de ferro e outro de água. O "braço de ferro" traz com ele o comboio cuja passagem ameaça revolucionar tudo um pouco, da economia dos homens aos costumes da fauna. O "braço de água" organiza a vida de toda a comunidade e o rio corre tão naturalmente que impõe a própria aldeia: "as aldeias não escolheram 
o sítio para nascer". Mostrando um encantamento pelo mundo da água que contrasta com a diabolização do comboio, esse "Cavalo do Diabo" - ou, no dizer de Álvaro Cunhal em Até Amanhã Camaradas, esse "estardalhaço de metal e vapor" (Cunhal 1998 [?]: 73) -, Redol acaba ainda assim por não preferir a correnteza da água em detrimento do estardalhaço do ferro, acusando ambos os braços de se unirem num "abraço apertado" que diz esmagar quem fica entre eles (Redol 1999 [1946]: 26).

Dez anos depois de Porto Manso, Redol conseguirá por fim libertar-se do sufoco daquele "abraço apertado". Com A Vida Mágica da Sementinha - uma Breve História do Trigo, Redol estreia-se na literatura infantil. O livro de 1956 ensaia uma pequena ficção científica que começa na própria capa, onde uma ilustração de Rogério Ribeiro desenha o corte horizontal de uma semente ampliada ao microscópio. Longe do criticismo angustiado de Porto Manso, Redol apresenta agora a simpática figura de Mitchurin, "um homem de aparência insignificante" que abandonou a tarefa quotidiana de acertar o relógio da estação do caminho-de-ferro para ir viver no campo, onde compra um pequeno pomar. Liberto do rigorismo do relógio - "o tempo nunca mais contou" - Mitchurin transforma o pomar num "laboratório de tipo novo" e durante anos experimenta, experimenta de novo e de novo volta a experimentar. Sem respeitar a purismos e sem obedecer a fronteiras, "levava pólen de umas flores para outras, casava uma macieira russa como outra de origem francesa, fazia frutos inteiramente desconhecidos, cruzando uma certa espécie de maçã com cerejas, ameixas e outros frutos", iniciando uma aventura que leva Redol a sonhar um novo mundo de "trigos vedetas, como as do cinema e do teatro", trigos que "vão chegar a toda a parte, mesmo àquelas terras áridas e secas como os desertos".

Levando consigo o saber científico e o know-how tecnológico da cidade e passando pela vergonha de ser gozado pela aldeia que o acolhe, abandonando os caminhos-de-ferro para regressar ao pomar e por fim revolucionar a produção a tal ponto que "agora tudo parece possível", Mitchurin abriu à humanidade uma nova era: "A civilização habituou-se a viajar de avião: todos os dias a ciência a leva mais depressa. E caminharemos sempre com ela na companhia de novos trigos", trigos que dispensam mecanização, trigos dos quais o pão nasce sem que as mãos toquem em farinhas, trigos que de uma só fábrica se alimenta Lisboa inteira (Redol 1956: 74-77). Com Mitchurin, Redol concretizou de forma mais plena do que antes a ambicionada fusão entre primitivo e civilização, procurando reunir a aura mágica do primeiro e a ficção científica da segunda.

Inspirado na história do Michurin soviético, o Mitchurin de Redol surge no entanto como uma variante do Michurin dominante nos anos 50 entre os comunistas do PCP. Como é sabido, Ivan Vladimirovich Michurin foi uma das primeiras personalidades a ser cientificamente consagradas pelo Estado soviético ainda nos anos 20, sob iniciativa de Lenine e por obra e graça dos sucessos 
das suas inovações genéticas no campo da agricultura, as quais se diziam devidas a décadas de experimentações práticas. Nos anos 30, no entanto, Ivan Vladimirovich Michurin foi transformado em referência fundadora do lyssenkismo e o seu experimentalismo tornou-se daí em diante numa fonte de legitimação das posições produtivistas dos comunistas soviéticos, segundo as quais havia que forçar a natureza de modo a retirar dela aquilo que ela por si só não poderia dar. Em Portugal, é este Ivan Vladimirovich Michurin que impera entre os comunistas (por exemplo, a argumentação dos dirigentes comunistas contra a tese salazarista do "Portugal é um país pobre" inspira-se em boa medida na retórica produtivista soviética). Ora, comparativamente a este Michurin, o Mitchurin de Redol assumiu uma visão bem mais romântica da natureza, o que acontece porque Redol o cria à imagem da sua aspiração revolucionária.

Fazendo esta seguir a espiral de um ciclo, a revolução comunista de Redol rompia quer com o restitucionismo dos românticos quer com o progressivismo dos comunistas, abrindo caminho à hipótese de um comunismo romântico. À idealização de uma alteridade irredutível pelos primeiros opunha Redol a ideia de que só era possível um regresso que ousasse avançar. Em 1964, poucos anos antes de morrer, no prefácio para o Romanceiro Geral do Povo Português, Redol deixava claro que para ele só se poderia retornar à comunidade avançando em direcção ao mundo:

O mundo é agora um corpo único, talvez ainda com mais de um coração, mas com o mesmo sangue. A história é uma marcha, dramática e viril, exultante e angustiada, que o homem vem a empreender do rebanho para o homem individualizado e plural, consciente do seu lugar num todo solidário (Lopes-Graça, Redol e Keil 1964: 1).

E à imposição de um economicismo industrializante pelos segundos opunha Redol a ideia de que só era possível avançar através de um regresso. Por isso, em A Vida Mágica da Sementinha, no mesmo período em que dirigentes comunistas como Júlio Fogaça e Álvaro Cunhal fazem da modernização da agricultura a base para a reconstrução da comunidade económica nacional, Redol cai na tentação de religar o tempo da cidade e o tempo da aldeia em nome de um tempo simultaneamente pré-nacional - um tempo que não se cronometra, contrariamente ao tempo da estação de comboio - e pós-nacional - o tempo do avião cuja velocidade dissolve no ar tudo o que é sólido.

Por tudo isto, o caso de Alves Redol é um dos mais claros testemunhos da pluralidade de sentidos que está em jogo nas representações dos intelectuais comunistas. Começando por se diferenciar dos intelectuais comunistas de imaginação mais urbanista, Redol celebrou o comunismo primitivo. Enquanto a fascinação exótica de uma Maria Lamas se centrava na cidade e tendia para 
o cosmopolita - por exemplo, em 1948, na preparação de As Mulheres do Meu País, ela anota no caderno de viagem: "A cidade do Funchal, quando desembarcam passageiros de vapores ingleses, toma um aspecto colorido, vivo, alegre. Muitas cores, trajos variados, alguns exóticos, tornam monótono e velho, pelo contraste, o aspecto normal da cidade" (Lamas 1948) -, Redol estranhou elogiosamente o mundo rural e reconheceu-lhe possibilidades revolucionárias. Porém, o nosso escritor não se deixou encantar absolutamente por visões comunistas mais pastorais. Contrariamente ao que sucedeu na crítica do fado e no elogio à canção rústica em Fernando Lopes-Graça (Lopes-Graça 1991 [1953]: 174), Alves Redol não destilou qualquer tipo de ódio em relação ao mundo citadino e a sua descrição maquinal dos gaibéus ecoou, em variadíssimos sentidos, o elogio obreirista da modernidade industrial, elogio que era apanágio do sovietismo russo e que tinha um dos seus melhores exemplos num poema dos anos 30 escrito pelo camarada vila-franquense de Redol, António Dias Lourenço, poema no qual se saudava os "homens de cor de cimento e de ferrugem" (Lourenço 1939: 3). ${ }^{25}$

Começando por romper o tempo em dois através de textos como Glória - Uma Aldeia do Ribatejo, Alves Redol identificou a aldeia como alteridade face à cidade na mesma medida em que a colónia lhe surgira em alteridade face à metrópole; contudo, posteriormente, em textos como Gaibéus e A Vida Mágica da Sementinha, Redol fez questão de convidar a cidade a mergulhar na aldeia, propondo assim religar ambos os tempos e ambicionando a uma nova unidade comunitária. Seduzido tanto por interpretações obreiristas mais produtivistas como por uma visão romântica e ruralista, Redol procurou sair da encruzilhada reinventando o seu comunismo através do seu romantismo e procurando ir mais além da simples demarcação de uma linha de fronteira entre o tempo da civilização e o tempo do primitivismo.

25 Intitulado "Balada do fumo negro", o poema de Dias Lourenço é publicado em 1939 no Mensageiro do Ribatejo. Constitui todo um programa de uma civilização operária: "[...] Eu te saúdo, ó fumo negro das fábricas!/ Eu te saúdo!/ Aí onde maculas o azul,/ Onde rolas ao sabor da ventania,/ Há homens que o carvão tingiu de negro,/ Homens verdes, brancos, amarelos,/ Homens cor do cimento e da ferrugem,/ Homens sem raça!/ Homens sem cor!” (Lourenço 1939: 3). 


\section{BREVE NOTA PARA O RECOLHEDOR DO CANCIONEIRO POPULAR DO DOURO}

(Alves Redol: 195-)

Em cada localidade procurar as pessoas mais idosas, cuja fama nas diversões e ranchos do trabalho do seu tempo, asseguram a possibilidade de farto manancial de poesia popular. Fazer com elas, três no máximo, alguns serões de recolha, para que se auxiliem no avivar da memória, cabendo somente ao recolhedor a tarefa de escrever.

Em caso de impossibilidade, recolher com uma só pessoa, procurando o recolhedor citar algumas quadras que conheça, a fim de que o fenómeno de irrupção, chamemos-lhe assim, se produza mais facilmente.

Entendem as pessoas idosas, na generalidade, que os versos do seu tempo nada valem, depois do que ouvem pela telefonia. É necessário convencê-las de que, entre os homens cultos de todo o mundo, é bem outra a opinião, e que prestam um alto serviço, comunicando o que sabem.

Nunca se deve enjeitar qualquer quadra, mesmo que pareça de má qualidade poética - o facto não só desgosta os nossos informadores, o que prejudica o colectivo, como ainda pode fazer perder alguma peça bastante preciosa.

Feita a recolha, verificar se há quadras alusivas aos seguintes temas: - Região - Montes ou serras - Localidades - Lugares das localidades - Fontes - Quintas - Rios ou ribeiros - Usos da terra - Santos - Festas - Quadras aos astros, à flora (árvores, ervas, frutos, etc.) e à fauna (animais); Quanto à pessoa humana: - Nascimento - Baptismo - Nomes - Vestuário - Amor - Namoro - Cartas (quadras que falem de cartas) - Ciúmes - Zangas - Bailaricos e danças - Cantigas de escárnio e mal-dizer - Vida militar - Saudades - Tristeza - Maliciosas - Beijos - Casamento - Filhos - Morte - Tarefas do campo e do rio (cavas, empas, podas, etc.) - Profissões do campo ou do rio - Quadras ao vinho, à vindima, às uvas, e a qualquer produção agrícola (azeite, centeio, etc.).

Quadras que falem de trabalho, de comer, dos cardenhos, das regas, dos contratos, dos pagamentos, dos feitores, dos caseiros, e patróes, dos maus tratos, etc.

Quadras alusivas à filoxera, às cheias do rio, às tempestades e às crises do Douro (falta de venda do vinho, pagamentos baixos, etc.).

O facto de se citarem aviva a recordação dos nossos informadores e lega-nos preciosos documentos para o futuro.

Tudo deve ser recolhido e enviado.

Na hipótese de haver na localidade qualquer poeta popular, mesmo jovem, fazer recolha, em sessões preparadas, das suas quadras ou cantigas glosadas, comunicando-as com o seu nome.

O recolhedor deve ter sempre presente que presta um alto sérvio ao Douro e À cultura nacional, bastando-lhe esta certeza para que procure remover dificuldades e revestir-se de alguma paciência, que bem precisa se torna para tão árdua tarefa.

Com as quadras remetidas não esquecer os nomes dos indivíduos que prestaram informações $e$ do seu recolhedor, porque todos devem mencionar-se no livro em preparação, Cancioneiro Popular do Douro, que só será possível por um esforço colectivo, de quantos compreendam a utilidade desta iniciativa.

Fonte: MARINHO, Maria José, e António Mota Redol (eds.), 2000, Alves Redol

- Testemunhos dos seus Contemporâneos, Lisboa. Caminho, página 287. 


\section{BIBLIOGRAFIA}

AMADO, 1936 [1933], Cacau. Rio de Janeiro, José Olympio.

BRITO, Nogueira de, 1936, "O Tango", O Diabo, edição de 18-10-1936, página 3.

—_, 1938, "Glória - Uma aldeia do Ribatejo”, O Diabo, edição de 23-10-1938, página 7.

CUNHAL, Álvaro, 1998 [?], Até Amanhã Camaradas, Lisboa, Edições Avante!.

DIONÍSIO, Mário, 1951, "Os homens e as sombras, Alves Redol”, Vértice, 97, pp. 500-501.

FABIAN, Johannes, 1983, Time and the Other - How Anthropology Makes its Object. Nova

Iorque, Columbia University Press.

Ferreira, Ana Paula, 1992, Alves Redol e o Neo-realismo Português. Lisboa, Caminho.

Jornal de Notícias, 1959, "Alves Redol esteve no Porto", edição de 24-12-1959, página 14.

LAMAS, Maria, 1948, "Apontamentos para As Mulheres no Meu País", em Espólio Maria

Lamas, E28, Cx. 18.

LEAL, João, 2000, Etnografias Portuguesas - Cultura Popular e Identidade Nacional (1870-1970),

Lisboa, Dom Quixote.

LOPES-GRAÇA, Fernando, Alves Redol, e Maria Keil, 1964, Romanceiro Geral do Povo Português. Lisboa, Iniciativas Editoriais.

LOPES-GRAÇA, Fernando, 1991 [1953], A Canção Popular Portuguesa. Lisboa, Caminho.

LOSA, Margarida, 1998, From Realist Novel to Working-class Romance: an Introduction to the Study of the Brazilian, Italian and Portuguese New Social Realist. Nova Iorque, New York University, 1988.

LOURENÇO, António Dias, 1939, "Balada do fumo negro", Mensageiro do Ribatejo, edição de 9-7-1939, página 3.

LÖWY, Michael, e Robert Sayre,1997, Revolta e Melancolia - O Romantismo contra a Corrente da Modernidade. Venda Nova, Bertrand Editora.

MARINHO, Maria José, e António Mota Redol (eds.), 2000, Alves Redol - Testemunhos dos Seus Contemporâneos. Lisboa, Caminho.

O Diabo, 1936, "No IV Centenário de Gil Vicente - Um que amou o povo e por amor dele desceu à rua”, edição de 8-3-36, página 1 .

— 1939, "Cultura e realidade nacional", edição de 7-1-1939, página 1.

PITA, António Pedro, 2002, Conflito e Unidade no Neo-Realismo Português. Porto, Campo das Letras.

REDOL, Alves, 1927, “Toiros”, Vida Ribatejana, edição de 31-7-1927, página 2.

—_, 1928a, "De longe... (partida)", Vida Ribatejana, edição de 16-09-1928, página 3.

__, 1928b, "De longe... (aspectos)", Vida Ribatejana, edição de 30-9-1928, página 4.

—_, 1928c, "De longe... (Madeira)", Vida Ribatejana, edição de 14-10-1928, página 3.

—, 1928d, "De longe... (Farrapos)", Vida Ribatejana, edição de 4-11-1928, página 3.

__, 1928e, "De longe... (S. Tomé)", Vida Ribatejana, edição de 2-12-1928, página 4.

__, 1929a, "De longe... (História)", Vida Ribatejana, edição de 10-3-1929, página 5.

—_, 1929b, "De longe... Ressurgimento?”, Vida Ribatejana, edição de 7-4-1929, página 3.

__, 1930, "De longe...", Vida Ribatejana, edição de 27-7-1930, página 2.

__, 1931, "Poente”, Vida Ribatejana, edição de 29-11-1931, página 4.

—, 1932, "Aspectos da Feira", Vida Ribatejana, edição de 16-10-1932, p. 1.

_., 1934, "Gado Bravo - o Ribatejo no cinema", Mensageiro do Ribatejo, edição de 11-8-1934, página 1 .

—_, 1936a, "País de Trovadores", Mensageiro do Ribatejo, edição de 17-5-1936, página 1. 
REDOL, Alves, 1936b, “Kangondo”, O Diabo, edição de 29-11-1936, página 2.

_-, 1937a, "De sol a sol - O Tejo”, O Diabo, edição de 24-1-1937, página 4.

—_, 1937b, "As Lezírias - um pouco da sua história e algumas das suas histórias...", O Diabo, edição de 9-5-1937, página 7.

—_, 1937c, “Campinos”, O Diabo, edição de 13-6-1937, página 7.

__, 1938, Glória - Uma Aldeia do Ribatejo. Barcelos, edição do autor.

—_, 1939, "Abertura", Mensageiro do Ribatejo, edição de 14-5-1939, página 3.

__, 1940a, "O trabalho no Cancioneiro do Ribatejo", O Diabo, edição de 17-8-1940, p. 3.

—, 1940b, Nasci com Passaporte de Turista. Lisboa, Portugália.

—, 1945-1952, "Ribatejo”, em João de Barros (org.), Portugal Maravilhoso, vol. II. Lisboa, Edições Universo, pp. 90-176.

—_, 1947 (?), A França - Da Resistência à Renascença. Lisboa, Editorial Inquérito.

_-, 1950, Cancioneiro do Ribatejo. Vila Franca de Xira, Centro Bibliográfico.

—_, 1956, A Vida Mágica da Sementinha - Uma Breve História do Trigo. Lisboa, edição de autor.

— 1968 [1942], Avieiros. Lisboa, Publicações Europa-América.

—_, 1979 [1939], Gaibéus. Lisboa, Publicações Europa-América.

—_, 1979 [1965], "Breve memória - para os que têm menos de 40 anos ou para quantos já esqueceram o que aconteceu em 1939”, em Alves Redol, 1979 [1939], Gaibéus. Lisboa, Publicações Europa-América.

— 1999 [1946], Porto Manso. Lisboa, Caminho.

República, "O escritor Alves Redol homenageado na Cooperativa Piedense", edição de 1-8-1962, página 14.

SÁ, Victor de, 1963 [1956], "A tradição do ano (Póvoa do Varzim)", Actas do $1^{\circ}$ Congresso de Etnografia e Folclore, vol. II. Lisboa, Biblioteca Social e Corporativa, pp. 363-368.

SAlEMA, Álvaro, 1980, Alves Redol - A Obra e o Homem. Lisboa, Arcádia.

SCOTT, James C., 1985, Weapons of the Weak - Everyday Forms of Peasant Resistance. New Haven, Yale University Press.

SILVA, Garcez da, 1990, Alves Redol e o Grupo Neo-realista de Vila Franca. Lisboa, Caminho. —_, 1993, A Experiência Africana de Alves Redol. Lisboa, Caminho.

TORRES, Alexandre Pinheiro, 1979, Os Romances de Alves Redol. Lisboa, Moraes Editores. 


\section{The magical-scientific communism of Alves Redol}

José Neves

Investigador do Centro de Estudos de História Contemporânea do ISCTE.

nevesze@hotmail.com

Considering ethnography's relevance in new social realism, this article focuses the case of the writer Alves Redol, an emblematic personality of that literary movement. Through an analysis of the making-of an ethnographic sensibility in Redol, we reflect upon the communist meaning of such sensibility and the effect it had on Redol's own representations of the people and the nation. Then we will confront such representations with Redol romantic aspiration towards a primitive communism but also his desire for an industrial labourization of the rural life, to conclude that Redol overstepped the city/country dichotomy and moved away from both urban and rural imaginary, a move that reached his maximum eloquence in the figure of Mitchurin, the main-star of $A$ Vida Mágica da Sementinha.

KEYWORDS: Alves Redol, new social realism, communism, nationalism, ethnography, tradition. 